\title{
A língua dos índios Xetá como dialeto Guaraní
}

\author{
Aryon Dall'Igna Rodrigues
}

Os índios da Serra dos Dourados, PR, só se tornaram conhecidos na década de 1950 e só começaram a ser estudados a partir de 1956 (Fernandes, 1958). As primeiras observações sobre sua língua provocaram a hipótese de que se tratasse de uma língua tupí-guaraní fortemente mesclada com elementos estranhos: Guérios (1959, p.112) declara que "o xetá é uma língua mista no sentido de que há um considerável contingente aloglótico sobre a base tupí-guaraní", e Loukotka (1960, p.368) conclui que a língua "da tribo da Serra dos Dourados foi intensamente desagregada por influências estranhas, desconhecidas e indetermináveis". Essa hipótese parecia casar-se bem com a situação cultural daqueles índios, essencialmente caçadores e coletores ao contrário dos povos tipicamente tupí-guaranís, que são agricultores.

O primeiro antropólogo que deles se ocupou atribuiu-lhes o nome xetá (Fernandes, 1958), que se tornou mais ou menos corrente na literatura antropológica e que é uma das designações dos "botocudos" do rio Ivai, PR, referidos de meados do século passado à primeira década do século XX sob diferentes nomes: bugres (Elliot, 1869), botocudos (Keller [1867] em Lovato, 1974; Bigg-Wither, 1878), aré (Borba, 1904, 1908), notobotocudos (Ihering, 1907), xetá [ššetá, šetá] (Frič, 1909, 1943; Loukotka, 1929), yvaparé (Nimuendaju, 1914). A identificação dos índios da Serra dos Dourados com esses "botocudos" é ainda uma questão aberta.

Os dados colhidos por mim entre os índios da Serra dos Dourados de 1960 a 1962 e em 1967 revelam que se trata não apenas de uma língua da família tupí-guaraní, mas de um idioma que se filia imediatamente ao grupo dialetal guaraní (cf. Guérios, 1959, p.112) e que não sustenta a hipótese de tratar-se de língua mista ou fortemente influenciada por idioma estranho, não tupí-guaraní. A maior parte dos elementos divergentes, que levaram àquela hipótese, deve-se aos seguintes fatores: 
1) mudanças fonológicas que tornaram algumas palavras não imediatamente reconhecíveis como afins a suas correspondentes em Guaraní (os dados aqui utilizados são do Guaraní antigo, extraídos de Ruiz de Montoya, 1876, e fonemizados segundo Grannier Rodrigues, 1974); p. ex.: $a^{\prime}$ wãči neblina, em guaraní (g.) ibi'tĩ; 'ñoča espécie de palmeira, g. yu'yi; wa'rëke bebida (de coquinho), g. i'ba ri'kwe suco de fruta; há'wiča grande, g. hubi'cya; 'rãiča frio, g. ro'?i'cã ;

2) substituição de nomes tabuizados por outras designações, geralmente locuções descritivas; p. ex. 'haikã 'pĩrĩtai caça/carne malhada, em lugar de 'ñagwa onça, que corresponde ao guaraní ya'wa (re'te), 'haikã čape'ai caça/ carne que tem casca, em lugar de 'tato tatu, que corresponde ao g. ta'tu: 'haikã 'huuai caça/carne que faz huu, em lugar de ka'piwai capivara, que corresponde ao g. Kapi?i'ba;

3) substituição de nomes simples por locuções metafóricas que aludem a fatos míticos: p. ex.: 'ñane 'čape ta'kië nossa luz, irmão mais velho para o sol, em g. kwara'hi;; 'ñane 'čape 'tëweá nossa luz, irmão mais moço para a lua, em g. ya'ct; ta'tıka aldeia das estrelas para o céu, em g. i'bag; ta'tıkama'yetai introdutor (?) do céu para o gavião, em g. tawa'to;

4) substituição de nomes simples ou complexos por derivados ou compostos descritivos: p. ex.: haikã'ča (haikã $+e \check{c} \dot{t}+a$ ) assador de caça/carne, em lugar de 'ata fogo, que corresponde ao g. a'ta; 'ñane 'tata nossas estrelas, cujo segundo elemento corresponde ao segundo componente do g. ya'ci-ta'ta estrela; ñepra'ka o colhedor (g. yepora'ka'ha) para o machado, em g. yi; či mi'rata que eu faço andar comigo (g. cye remieroa'ta) para minha esposa, em g. cye remire'ko (literalmente a que eu faço estar/viver comigo); porõ'ha o pisador (g. pi'rũ'ha) para o pé, em g. pi; mã'ha o vedor (g. ma'?ế'ha) para o olho, em g. e'ca; poči'a o defecador (g. po'ti'ha) para o ânus, em g. e'bi'kwa (literalmente orifício das nádegas); 'moi či'waki cobra de braços para o lagarto, em g. te'yu;

5) substituição de nomes simples ou complexos por outros em consequência de extensões semânticas associadas ou não a mudanças culturais; p ex.: ta'pegwa esteira para dormir, em g. pi'ri (pế'mi), mas correspondente ao g. tatape'kwa abano para o fogo: a mesma peça tem ambas as serventias entre os índios da Serra dos Dourados; 'tagwa flauta, em g. mi'mi, mas correspondente ao g. $t a^{\prime} k w a$ taquara: as flautas da Serra dos Dourados são feitas de taquara; ka'nomi homem, em g. kuima'?e, mas correspondente ao g. kunumĩ menino: 'ñčoi sapo, em g. kuru'ru, mas correspondente ao g. yu'?i rã;

Embora nem todos os elementos lexicais registrados tenham podido ser identificados, até agora, com elementos guaranís conhecidos, parece certo, entretanto, que não há nenhuma evidência de intrusão de empréstimos lexicais de língua não tupí-guaraní no idiomados índios da Serra dos Dourados. As comparações com línguas não tupí-guaranís sugeridas por Guérios (1959, 
p. 107ss.) não têm força demonstrativa. Por uma parte, distribuem-se dispersamente por mais de vinte diferentes famílias linguísticas, a maioria das quais representada nas comparações por um único item lexical. Por outra parte, apreciável número dos elementos xetá assim comparados são daqueles que acabaram revelando-se seguramente tupí-guaraní ta'tıka céu (cf. 3 acima); o'tëkë chove, g. oti'ki pinga, goteja; 'ñane 'čape sol (cf. 3 acima), g. ya'ne ca'pe nossa luz; 'tagwa flauta, g. ta'kwa taquara.; 'nane ka'nomi homem, g. ya'ne kunu'mĩ nosso menino; 'čarii velha, g. ya'riy avó: pi'apo coruja; g. pi'ha'po habitante da noite; ë'wa 'reki, wa'rëki bebida (de coco de jerivá), g. i'ba rikwe suco de fruta; ha'wiča grande, g. hubi'cya grande.

A comparação sistemática da língua da Serra dos Dourados com as demais línguas da família tupí-guaraní mostra que tanto a fonologia quanto o léxico daquela são deriváveis mais imediatamente do grupo dialetal guaraní que de qualquer dos outros ramos da família. Peculiaridades lexicais e fonológicas do grupo guaraní encontram-se também no xetá da Serra dos Dourados: 'mopi morcego corresponde ao g. mo'pi, que se distingue do tupinambá e outras línguas tupí-guaraní ani'ra; 'këče ter medo, corresponde ao g. kihi'ye, uma metá-

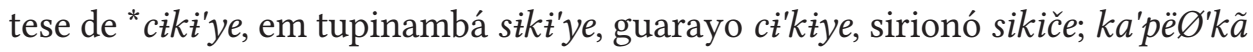
irmã mais moça da mulher corresponde ao g. kipit'?t, que difere por metátese do tupinambá piki'?itr. Correspondendo ao tupinambá $s$, sirionó $s$, guarayo c. o guaraní antigo tem ora $c$, ora $h$, e o guaraní moderno do Paraná (mbiá), paralelamente, ora $\check{c}$, ora Ø; o xetá da Serra dos Dourados acompanha essa distribuição, com č e Ø: pi'o vocês vão, em g. ant. pe'ho, g. Pná. pe'o, tupinambá pe'so; 'poi pesado, g. ant. po'hìy, g. Pná. po'tiy, t. po'siy; mas, ča corda, g. ant. cã, g. Pná. čã, t. sam; čo morder, g. ant. cu'?u, g. Pná. ču'?u, t. su'?u; 'rãiča frio, g. ant. ro'?iccã, g. Pná. ro?ìcãa; t. ro'Pisay. (Os dados do guaraní do Paraná - mbiá do rio das Cobras - são de Edna Aaron, apud Lemle, 1971).

A principal inovação fonológica do xetá da Serra dos Dourados parece ter sido a mudança da regra de acento: enquanto o acento de intensidade em guaraní antigo recaía sistematicamente na última sílaba dos temas nominais e verbais, houve em xetá um deslocamento para a penúltima sílaba: o'gwiče desce, g. owe'yi; 'heče nele, g. he'ce; 'îka osso dele, g. i'kã; 'ita pedra, g. i'ta; i'ača atravessar rio, g. ía'ca; ia'ča ponte (de *ia'čaa, atravessadouro). g. íaca'ha; 'koto furar, g. ku'tu; a'wira árvore, g. ìtb'ra.

A essa mudança do acento associa-se a lenização das consoantes oclusivas, que de fortes passam a lenes e se realizam frequentemente como fricativas nas sílabas tornadas átonas: 'pepo ['pebA], ['peßA], ['peßa], asa, pena da asa, g. pe'po: 'oke [Agj] dorme, g. o'ke; -'áco ['ajo] grande, g. -wacu, ha'meta [ha'meřa] tembetá dele, g. heme'ta; etc. 
Entre outras inovações fonológicas, destacam-se as seguintes:

- eliminação da oclusiva glotal intervocálica: 'aaeu caio, g. a'?a;

- eliminação da fricativa glotal intervocálica: $p \dot{t}-' a$ ['pia] noite, g. pit'ha;

- assilabação das vogais altas contíguas a outra vogal: 'tau [taw] vou comer, g. ta'?u; ta'čau [ta'j̃aw] vou tomar banho g. taya'hu; 'hai [hay] mamãe, g. ha'?i; mu'ako ['mwako] aquecer, g. moa'ku;

- abaixamento da vogal central alta em sílaba átona: $a^{\prime} w i r a$ árvore, g. ìbi'ra; 'ëwa chão, g. i'bi;

- abaixamento das vogais posteriores $u$, o: 'točo barro, g. tu'yu; ' moms ['mom $\alpha$ ] atirar, g. mo'mo;

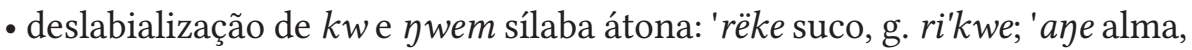
g. $a^{\prime} \eta w e$

- substituição de $b[\beta]$ por w: 'ëwo flechar, g. i-'bõ; $a^{\prime}$ woto vento, g. ìbi'tu;

- nasalização aparentemente imotivada de $y$ e $w$ iniciais: 'ño espinho g. ' $y u$; 'ñoča palmeira (esp.), g. yu'yi; ' ñako jacu, g. ya'ku; 'ñčo arco-íris. g. yit'?i; 'ñčoi

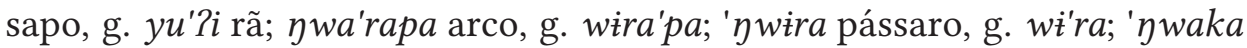
arara vermelha, g. $w a^{\prime} k a$.

\section{Referências Bibliográficas}

Bigg-Wither, Thomas, P. 1878. Pioneering is South Brazil, 2 vols. Londres. Tradução: Novo caminho no Brasi1 meridional: a Província do Paraná. Rio de Janeiro. 1974. Borba, Telemaco. 1904. Observações sobre os indígenas do Estado do Paraná. Revista do Museu Paulista.6:53-62. São Paulo.

Borba, Telemaco. 1908. Actualidade indígena: Paraná, Brazil. Curitiba.

Elliot, John H. 1869. Resumo do itinerário de uma viagem exploradora pelos rios Verde, Itareré, Paranapanêma e seus afluentes, pelo rio Parana, Ivahy, e sertões adjacentes, emprehendida por ordem do Exm. Sr. barão de Antonina. Revista Trimestral de Historia e Geographia do Instituto Historico e Geographico Brasileiro 9 (2. ${ }^{\text {a }}$ ed.):17-42. Rio de Janeiro.

Fernandes, José Loureiro. 1958. Os índios da Serra dos Dourados (os xetá). Anais da III Reunião Brasileira de Antropologia 27-46. Recife.

Frič, Albert V. 1908. Kaingánové, lovci otroku: črta z Paraná. Daleky kraj 1:47-62. Praga.

Frič, Albert V. 1943. Indiáni Jižni Ameriky. Praga.

Grannier Rodrigues, Daniele Marcelle. 1974. Fonologia do guaraní antigo. Dissertação de Mestrado. Universidade Estadual de Campinas. Campinas.

Guérios, R. F. Mansur. 1959. A posição linguística do xetá. Letras 10:92-114. Curitiba. Ihering, Hermann Von. 1907. A anthropologia do Estado de São Paulo. Revista do Museu Paulista 7:202-257. São Paulo.

Lemle, Miriam. 1971. Internal Classification of the Tupí-Guaraní Linguistic Family. Tupi Studies I (David Bendor-Samuel, ed.) 107-129. Norman. 
Loukotka, Čestmir. 1929. Le Setá, un nouveau dialecte Tupi. Journal de la Société des Américanistes, n.s., 21: 373-398. Paris.

Loukotka, Čestmír. 1960. Une tribu indienne peu connue dans l'état brésilien Paraná. Acta Ethnographica Academiae Scientiarum Hungaricae 9 (3-4): 329-368. Budapeste.

Lovato, Lêda A. 1974. A Contribuição de Fritz KeIler à Etnografia do Paraná. Boletim do Museu do Índio, Antropologia 1. Rio de Janeiro.

Ruiz de Montoya, Antonio. 1876. Vocabulario y tesoro de la lengua guaraní, ó más bien tupí. Nueva edición. Viena e Paris. 